\title{
BMJ
}

\section{Use of fertility drugs and risk of ovarian cancer: Danish population based cohort study}

\author{
Allan Jensen, assistant professor of cancer epidemiology, ${ }^{1}$ Heidi Sharif, specialist in obstetrics and \\ gynaecology, ${ }^{1}$ Kirsten Frederiksen, associate professor of medical statistics, ${ }^{1}$ Susanne Krüger Kjær, \\ professor of cancer epidemiology $y^{1,2}$
}

${ }^{1}$ Danish Cancer Society, Institute of Cancer Epidemiology,

Strandboulevarden 49, DK-2100, Copenhagen, Denmark

${ }^{2}$ The Juliane Marie Center, Copenhagen University Hospital, Correspondence to: A Jensen allan@cancer.dk

Cite this as: BMJ 2009;338:b249 doi:10.1136/bmi.b249

\section{ABSTRACT}

Objective To examine the effects of fertility drugs on overall risk of ovarian cancer using data from a large cohort of infertile women.

Design Population based cohort study.

Setting Danish hospitals and private fertility clinics.

Participants 54362 women with infertility problems referred to all Danish fertility clinics during 1963-98. The median age at first evaluation of infertility was 30 years (range 16-55 years), and the median age at the end of follow-up was 47 (range 18-81) years. Included in the analysis were 156 women with invasive epithelial ovarian cancer (cases) and 1241 subcohort members identified in the cohort during follow-up in 2006.

Main outcome measure Effect of four groups of fertility drugs (gonadotrophins, clomifene citrate, human chorionic gonadotrophin, and gonadotrophin releasing hormone) on overall risk of ovarian cancer after adjustment for potential confounding factors.

Results Analyses within cohort showed no overall increased risk of ovarian cancer after any use of gonadotrophins (rate ratio $0.83,95 \%$ confidence interval 0.50 to 1.37$)$, clomifene $(1.14,0.79$ to 1.64$)$, human chorionic gonadotrophin $(0.89,0.62$ to 1.29$)$, or gonadotrophin releasing hormone $(0.80,0.42$ to 1.51$)$. Furthermore, no associations were found between all four groups of fertility drugs and number of cycles of use, length of follow-up, or parity.

Conclusion No convincing association was found between use of fertility drugs and risk of ovarian cancer.

\section{INTRODUCTION}

One of the best established risk factors for ovarian cancer is parity, with nulliparous women having a higher risk than parous women. ${ }^{1-3}$ Furthermore, an association may also exist between infertility, fertility drugs, and risk of ovarian cancer. In view of the large, constantly growing number of women requesting fertility treatment and the high incidences of ovarian cancer in most Western countries, the question of whether fertility drugs increase the risk of ovarian cancer has received much public attention and resulted in patient anxiety since the late 1970s.
Concern was intensified by the results of three epidemiological studies, which showed increased risks of ovarian cancer among women treated with fertility drugs, ${ }^{4-6}$ particularly nulliparous women and those who had used fertility drugs long term. Several subsequent epidemiological studies were largely reassuring as they did not confirm a strong link between use of fertility drugs and risk of ovarian cancer. ${ }^{7-21}$ Many of these studies, however, had methodological limitations: the cohort studies were of small size, had short and incomplete follow-up, and did not control for potential confounders, and the case-control studies had problems with the validity of reported drug use. ${ }^{22}$ Furthermore, most studies were not able to distinguish the possible effects of fertility drugs from the underlying causes of infertility, which could independently affect the risk of ovarian cancer. ${ }^{4-1523-26}$

The two most recent studies, a case-cohort study ${ }^{19}$ and a case-control study, ${ }^{20}$ showed no overall increase in the incidence of ovarian cancer after use of clomifene citrate or gonadotrophins. We established a cohort of 54362 Danish women who attended infertility clinics during 1963-98. This potentially represents the largest number of cases of ovarian cancer in any cohort of women with infertility problems to date. We also obtained extensive information about the women's drug histories and potential confounders. A previous analysis ${ }^{27}$ showed that the women in this cohort had a $46 \%$ higher risk of ovarian cancer than women in the general Danish population after adjustment for parity, which indicates that the increased risk might be associated with infertility related factors other than lower parity. We evaluated the effects of different fertility drugs on the risk of ovarian cancer in this cohort.

\section{METHODS}

The cohort has been described in detail in reports on studies of the association between use of fertility drugs and risks of breast cancer, ${ }^{28}$ thyroid cancer, ${ }^{29}$ and malignant melanoma. ${ }^{30}$ Briefly, the cohort comprised women with infertility referred to all Danish hospitals or private infertility clinics during 1963-98. In addition we included all women with a diagnosis of infertility 
(codes 628 and DN97, international classification of diseases, eighth and 10th revisions, respectively) recorded in the national patient registry, a nationwide register of virtually all discharges for somatic conditions from Danish hospitals since 1977. A total of 54449 women with primary or secondary infertility were enrolled. All data were entered into a single database, with one record for each woman, including the initial date that infertility was evaluated, the clinic's name, and the woman's civil registry number. To verify the personal identification number and to determine the date of migration or death, we linked the cohort to the population based civil registration system, with the civil registry number as the key identifier. Of the 54449 infertile women, all but 87 had a valid civil registry number, leaving 54362 women in the cohort for analysis.

\section{Identification of cases}

To determine the women's status for ovarian cancer after enrolment in the study, we used the civil registry numbers to link the cohort to the Danish Cancer Registry and the Danish Registry of Pathology. The cancer registry contains nationwide information on all incident cases of invasive cancer in Denmark since 1943, and the pathology registry contains information on specimens from all Danish public and private pathology departments and is updated daily. Because the cancer registry was updated only until 31 December 2003 at the time of analysis we used the pathology register to determine ovarian cancer status in the cohort

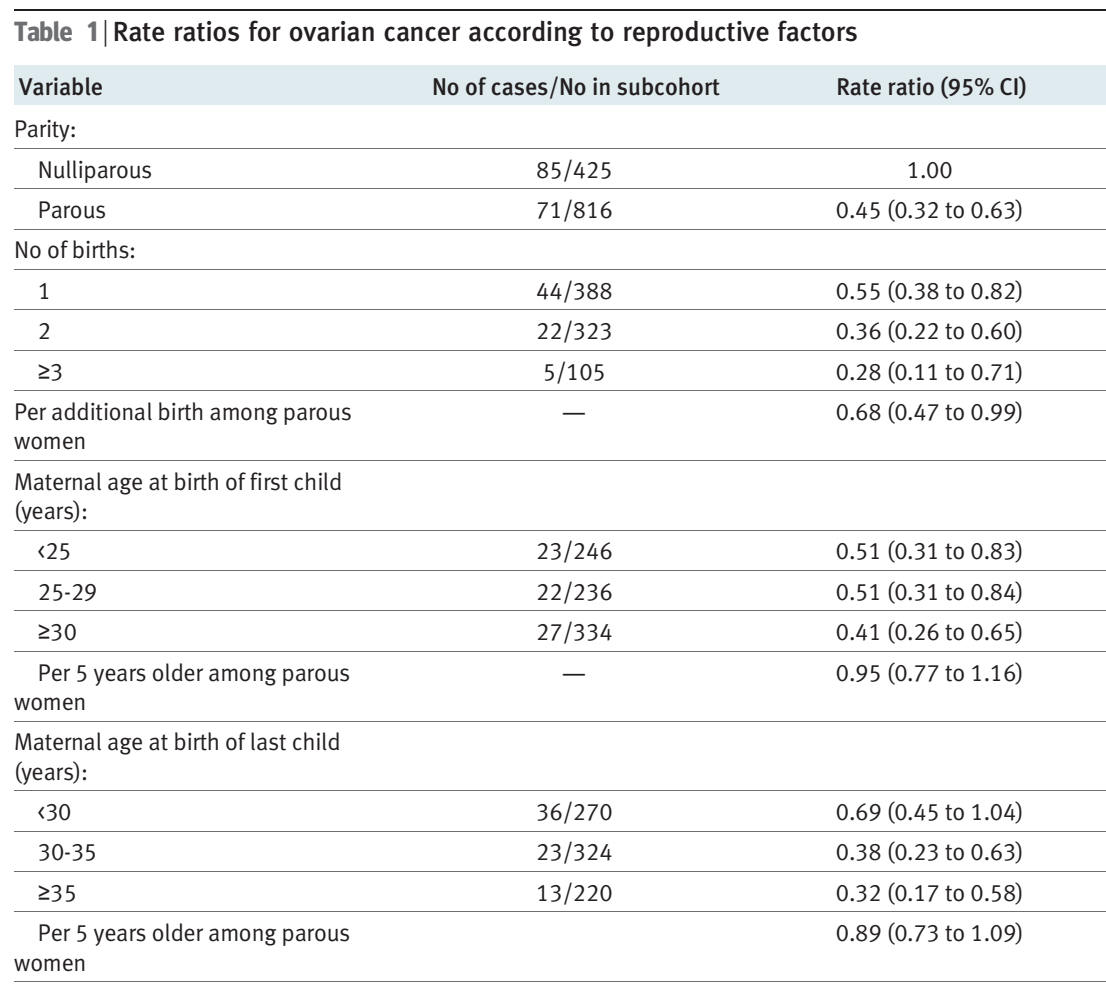

All analyses stratified according to calendar year (in categories) and age at start of follow-up (in categories) All rate ratios (except parity) adjusted for parity (nulliparous/parous) and number of additional births (linear) from 1 January 2004. We followed the cohort for occurrence of ovarian cancer from the first date infertility was evaluated until date of emigration, date of death, or 30 June 2006, whichever occurred first. Invasive ovarian cancer was diagnosed in 193 women during follow-up. For the present analysis we excluded 11 women with non-epithelial ovarian cancer and six women with ovarian cancer of unspecific histological type, leaving 176 women with epithelial ovarian cancer in the study.

\section{Identification of the subcohort}

In the case-cohort design the experience of all cases is compared with that of a randomly selected subcohort. ${ }^{31}$ In the present study, we randomly selected 1360 women from the cohort in four strata according to age at entry into the cohort (18-26, 27-30, 31-36, and $\geq 37$ years) and five strata according to the year they entered the cohort (1965-77, 1978-84, 1985-9, 1990-6, and 1997-8).

\section{Ascertainment of drug use and potential confounders}

We collected hospital files and medical records on all infertility related visits for all the women in whom ovarian cancer developed and for members of the subcohort. The records could not be found for 18 women, and the cause of infertility for two women was found to be sterilisation, leaving 156 women with ovarian cancer $(89 \%)$ for analysis. In the subcohort we excluded 78 women because their hospital files could not be found, eight because a diagnosis of infertility could not be confirmed, and 33 because the cause of infertility was previous sterilisation, leaving 1241 women in the subcohort (91\%). Ovarian cancer was diagnosed in eight women in the subcohort during the follow-up period, and we therefore included these women both as cases and as members of the subcohort in the analyses.

Information was abstracted on medical interventions for infertility, including fertility drugs prescribed and the number of treatment cycles. For each treatment cycle we abstracted the dates of starting and stopping to define the windows of exposure to the drugs. We also intended to abstract information on the dosage of the drugs, but this information was recorded for only a few women. From the medical records we abstracted information about the causes of infertility and any use of oral contraceptives, but this information was also available for only a minority of the women. To obtain information on reproductive history for all the infertile women with ovarian cancer and for those in the subcohort, we linked the cohort to the civil registration system and the Danish National Birth Registry by the civil registry numbers. The population based national birth registry contains information on all births in Denmark since 1973. Thus we obtained information on reproductive history from 1973 onwards from this register and reproductive history before 1973 from the civil registration system, as this register allows linkage between parents and children. 


\section{Statistical analysis}

According to the sampling strategy we used the unweighted case-cohort approach ${ }^{3233}$ to estimate rate ratios for ovarian cancer in a Cox proportional hazard regression model, stratified according to the sampling strata (age and year of enrolment). We used age as the time scale to ensure that the estimates were based on comparisons of women of the same age. The analysis was corrected for delayed entry, such that women were considered at risk only from the age at first date infertility was evaluated. We estimated rate ratios as previously suggested, ${ }^{31}$ whereby all the women in the subcohort contributed to all the relevant risk sets until the end of the follow-up period as a result of diagnosis of cancer, death, migration, or censoring, whereas women outside the subcohort who were cases entered only their own risk set. The $95 \%$ confidence intervals were based on robust estimates of the variancecovariance matrix of the Cox regression variables.

We evaluated the effects on overall risk of ovarian cancer and risks for different histological subtypes according to use of the following fertility drugs: follicle stimulating hormone, human menopausal gonadotrophins, clomifene, human chorionic gonadotrophins, and gonadotrophin releasing hormone, measured as any use, number of cycles of use, and years since first use. In the analyses, however, we pooled the two gonadotrophins, follicle stimulating hormone and human menopausal gonadotrophins, into one group called gonadotrophins, as they have identical modes of action. The women in the cohort were also treated with a large number of other types of fertility drug, such as progesterone, estradiol, and diethylstilbestrol. We did not, however, analyse the effects of these heterogeneous fertility drugs as each was given to only a few women.

The 156 epithelial ovarian tumours included in the analyses were classified into five histological types on the basis of international classification of diseases for oncology codes from the Danish Cancer Register, and the Danish Registry of Pathology international classification of diseases (seventh revision): serous $(\mathrm{n}=90)$, mucinous $(n=12)$, endometrioid $(n=23)$, clear cell $(n=8)$, and other types of epithelial ovarian cancer $(n=23)$. Potential confounding factors investigated in the main analyses included parity (nulliparous or parous), number of additional births, maternal age at birth of first child, and maternal age at birth of last child. We entered all variables as time dependent covariables, which changed values at the ages at which new events occurred (for example, birth or start of new treatment cycle). Information on the causes of infertility and any use of oral contraceptives was not available for most women and were therefore not included in the main analyses but were analysed for the subset of women for whom this information was available. Statistical analyses were carried out with SAS/STAT version 8.2 .

\section{RESULTS}

The distribution of period of entry into the study and age at entry for the 54362 women in the cohort has been described previously. ${ }^{28}$ The median year for entry was 1989, the median age at first evaluation of infertility was 30 years, and the median age at the end of followup was 47 years. The women were followed up for a median of 16.0 years (range 0.0-42.6 years), with $25 \%$ followed for more than 23 years. The 54362 women contributed 957454 person years of observation. The median time from entry into the cohort and diagnosis of cancer was 14.5 years (range 0.02-34.2 years), and the age of the women at the time of diagnosis ranged from 25 to 68 years (median 46 years). Fertility drugs were used by 77 of the $156(49 \%)$ women with ovarian cancer and 615 of the $1241(50 \%)$ subcohort members. Clomifene was the most commonly used fertility drug, taken by 58 cases $(37 \%)$ and 415 subcohort members (33\%), followed by human chorionic gonadotrophins (31\% and 33\%), gonadotrophins (17\% and 15\%), and gonadotrophin releasing hormone $(10 \%$ and $9 \%)$.

\begin{tabular}{|c|c|c|c|c|c|c|c|c|}
\hline \multirow[b]{2}{*}{ Variables } & \multicolumn{4}{|c|}{ No with ovarian cancer/No in subcohort } & \multicolumn{4}{|c|}{ Adjusted rate ratio $(95 \% \mathrm{Cl})$} \\
\hline & Gonadotrophins* & Clomifene citrate & hCG & GnRH & Gonadotrophins* & Clomifene citrate & hCG & GnRH \\
\hline \multicolumn{9}{|l|}{ Use: } \\
\hline Never & $130 / 1057$ & $98 / 824$ & $107 / 828$ & $\begin{array}{l}141 / \\
1131\end{array}$ & 1.00 & 1.00 & 1.00 & 1.00 \\
\hline Ever & $26 / 184$ & $58 / 417$ & 49/413 & $15 / 110$ & $0.83(0.50$ to 1.37$)$ & 1.14 (0.79 to 1.64$)$ & $0.89(0.62$ to 1.29$)$ & 0.80 (0.42 to 1.51$)$ \\
\hline \multicolumn{9}{|c|}{ No of cycles: } \\
\hline $1-4$ & $18 / 130$ & $35 / 226$ & $31 / 232$ & $14 / 100$ & 0.74 (0.41 to 1.33$)$ & $1.27(0.83$ to 1.94$)$ & $0.96(0.62$ to 1.48$)$ & 0.81 (0.42 to 1.56$)$ \\
\hline $5-9$ & $7 / 46$ & $15 / 117$ & $13 / 121$ & $1 / 10$ & 1.09 (0.49 to 2.44$)$ & $1.03(0.57$ to 1.86$)$ & $0.86(0.47$ to 1.57$)$ & 0.68 (0.09 to 5.38$)$ \\
\hline$\geq 10$ & $1 / 8$ & $8 / 74$ & $5 / 60$ & $0 / 0$ & $0.96(0.09$ to 10.30$)$ & 0.92 (0.42 to 2.02$)$ & 0.70 (0.28 to 1.80$)$ & - \\
\hline \multicolumn{9}{|c|}{ Time since first use (years): } \\
\hline$<5$ & $8 / 3$ & $8 / 3$ & $9 / 3$ & $5 / 1$ & 0.67 (0.29 to 1.54$)$ & 0.80 (0.32 to 1.99$)$ & $0.78(0.35$ to 1.75$)$ & 0.72 (0.28 to 1.89$)$ \\
\hline $5-9$ & $12 / 33$ & $17 / 14$ & $16 / 26$ & $8 / 32$ & $1.12(0.58$ to 2.21$)$ & $1.48(0.80$ to 2.73$)$ & $1.22(0.67$ to 2.23$)$ & 0.99 (0.43 to 2.33$)$ \\
\hline $10-14$ & $5 / 77$ & $13 / 77$ & $10 / 81$ & $2 / 57$ & 0.80 (0.29 to 2.18$)$ & $0.99(0.53$ to 1.87$)$ & 0.83 (0.43 to 1.62$)$ & $0.60(0.13$ to 2.70$)$ \\
\hline$\geq 15$ & $1 / 71$ & $20 / 323$ & $14 / 303$ & $0 / 20$ & $0.44(0.06$ to 3.14$)$ & $1.18(0.70$ to 1.99$)$ & 0.78 (0.43 to 1.42$)$ & - \\
\hline
\end{tabular}

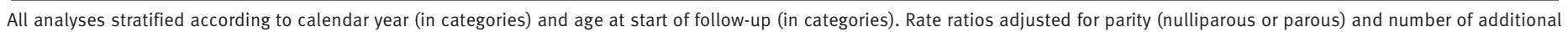
births (linear). hCG=human chorionic gonadotrophin; GnRH=gonadotrophin releasing hormone.

*Follicle stimulating hormone and human menopausal gonadotrophins. 
Table $3 \mid$ Rate ratios for ovarian cancer in nulliparous and parous women according to use of fertility drugs

\begin{tabular}{|c|c|c|c|c|c|}
\hline \multirow[b]{2}{*}{ Fertility drug and use } & \multicolumn{2}{|c|}{ Nulliparous women } & \multicolumn{2}{|c|}{ Parous women } & \multirow[b]{2}{*}{$\begin{array}{l}\text { Interaction } \\
\text { (P value) }\end{array}$} \\
\hline & $\begin{array}{l}\text { No with ovarian } \\
\text { cancer/No in } \\
\text { subcohort }\end{array}$ & Rate ratio $(95 \% \mathrm{Cl})$ & $\begin{array}{l}\text { No with ovarian } \\
\text { cancer/No in } \\
\text { subcohort }\end{array}$ & Rate ratio $(95 \% \mathrm{Cl})$ & \\
\hline \multicolumn{6}{|l|}{ Gonadotrophins*: } \\
\hline Never & $68 / 351$ & 1.00 & $62 / 706$ & 1.00 & \\
\hline Ever & $17 / 74$ & 0.85 (0.44 to 1.64$)$ & $9 / 110$ & 0.89 (0.43 to 1.83$)$ & 0.93 \\
\hline \multicolumn{6}{|l|}{ Clomifene citrate: } \\
\hline Never & $50 / 276$ & 1.00 & $48 / 548$ & 1.00 & \\
\hline Ever & $35 / 149$ & 1.28 (0.79 to 2.07$)$ & $23 / 268$ & 1.04 (0.61 to 1.78$)$ & 0.56 \\
\hline \multicolumn{6}{|l|}{ hCG: } \\
\hline Never & $57 / 285$ & 1.00 & $50 / 543$ & 1.00 & \\
\hline Ever & $28 / 140$ & 0.95 (0.57 to 1.58$)$ & $21 / 273$ & 0.87 (0.51 to 1.49$)$ & 0.81 \\
\hline \multicolumn{6}{|l|}{ GnRH: } \\
\hline Never & $75 / 369$ & 1.00 & $66 / 762$ & 1.00 & \\
\hline Ever & $10 / 56$ & $0.71(0.32$ to 1.54$)$ & $5 / 54$ & 1.09 (0.41 to 2.91$)$ & 0.48 \\
\hline
\end{tabular}

All analyses stratified according to calendar year (in categories) and age at start of follow-up (in categories). Rate ratios adjusted for parity (nulliparous or parous) and number of additional births (linear). hCG=human chorionic gonadotrophins; GnRH=gonadotrophin releasing hormone.

*Follicle stimulating hormone and human menopausal gonadotrophins.

Maternal age at birth of first and last child did not significantly affect the overall risk of ovarian cancer. In contrast, parous women had a notably lower risk than nulliparous women (rate ratio $0.45,95 \%$ confidence interval 0.32 to 0.63 ), which decreased with number of births (rate ratio $0.68,0.47$ to 0.99 ; table 1). Furthermore, the overall risk of ovarian cancer among women in the cohort was not significantly affected by either use of oral contraceptives (compared with ever use, the rate ratio for never use $0.46,0.20$ to 1.05 ) or causes of infertility (compared with anovulation, the rate ratio for tubal disease was $1.47,0.80$ to 2.68 , for endometriosis was $0.92,0.26$ to 3.31 , for uterine disorder was $0.65,0.14$ to 2.93 , and for male factor was $0.57,0.27$ to 1.24$)$.

After adjustment for parity and number of additional births, the overall risk of ovarian cancer was not significantly affected by use of any fertility drug (rate ratio $1.03,0.73$ to 1.47 ; data not shown), gonadotrophins $(0.83,0.50$ to 1.37$)$, clomifene $(1.14,0.79$ to 1.64$)$, human chorionic gonadotrophins $(0.89,0.62$ to 1.29$)$, or gonadotrophin releasing hormone $(0.80,0.42$ to 1.51 ; table 2). For all groups of fertility drugs the risk of ovarian cancer was not substantially different according to number of cycles of use or years since first use (table 2). For all four types of fertility drug, the overall risk of ovarian cancer was not noticeably affected by parity, and none of the interaction terms were statistically significant (table 3).

As a substantial proportion of the women in the cohort had used more than one type of infertility drug, the main effect of each type of drug was assessed. The general results were not changed when the risk of ovarian cancer was assessed only in those women who had used one type of fertility drug compared with never users (data not shown). When the rate ratios for the most prevalent combinations of fertility drugs were calculated, none of the five most commonly used combinations significantly affected risk: clomifene plus human chorionic gonadotrophins (rate ratio 1.13, 95\% confidence interval 0.71 to 1.80 ), clomifene plus gonadotrophins plus human chorionic gonadotrophins $(0.60,0.25$ to 1.42$)$, gonadotrophins plus human chorionic gonadotrophins plus gonadotrophin releasing hormone $(1.02,0.34$ to 3.03$)$, clomifene plus gonadotrophins plus human chorionic gonadotrophins plus gonadotrophin releasing hormone $(0.98$, 0.44 to 2.18 ), and clomifene plus gonadotrophins (2.20, 0.49 to 9.86$)$.

Table 4 presents the risks of different histological types of ovarian cancer. Of the 156 epithelial tumours, serous tumours constituted the majority $(58 \%)$, followed by endometrioid tumours $(15 \%)$, other tumours (15\%), mucinous tumours $(8 \%)$, and clear cell tumours $(5 \%)$. The risk of serous cancers was significantly increased after use of clomifene $(1.67,1.07$ to 2.61$)$. The increase in risk was found mainly among women followed for 15 years or more after first use of clomifene when compared with never use $(<5$ years $1.22,0.45$ to $3.34 ; 5-9$ years $1.76,0.87$ to $3.59,10-14$ years $1.23,0.58$ to $2.59, \geq 15$ years $2.17,1.15$ to 4.08$)$. The risk of serous cancer was not, however, related to the number of cycles using clomifene, and the risk did not differ according to parity (data not shown). A significantly decreased risk for other types of ovarian cancers was observed after use of human chorionic gonadotrophins $(0.24,0.08$ to 0.79$)$, whereas the risks for mucinous, endometrioid, and clear cell tumours were not significantly affected by use of any of the four groups of fertility drug.

To allow a minimum latency period between first use of fertility drugs and development of ovarian cancer, the few women with a diagnosis of ovarian cancer $(n=2)$ within one year after first use of fertility drugs were excluded from the analyses. Virtually no changes in the risk estimates were observed (data not shown), 
however, and therefore the results were not noticeably biased by a potential fertility drug induced acceleration of the growth of an existent ovarian tumour.

Finally, to evaluate the effects of various causes of infertility (anovulation, tubal disease, endometriosis, uterine disorder, cervical disorder, and male factor) and any use of oral contraceptives as potential confounders, all the analyses were adjusted for these two variables in the subsets of women for whom information was available: causes of infertility, $45 \%$ of cases and $51 \%$ of subcohort members, and any use of oral contraceptives, $33 \%$ of cases and $55 \%$ of subcohort members. None of the risk estimates changed noticeably after adjustment for these potential confounders (data not shown).

\section{DISCUSSION}

We found no convincing association between use of fertility drugs and the overall risk of ovarian cancer. Risk did not differ according to any use of fertility drugs, number of cycles of use, length of follow-up since first use of drug, or parity. Furthermore, none of the risk estimates was noticeably changed after adjustment for causes of infertility and any use of oral contraceptives in the subsets for which this information was available. When we analysed differences in risk according to histological subtype, however, a $67 \%$ increased risk for serous ovarian cancer after use of clomifene was found, primarily among women followed for 15 or more years.

\section{Strengths and limitations}

One of the most important strengths of the present study in comparison with earlier cohort studies is the precision of the risk estimates because of the large number $(n=156)$ of women with ovarian cancer studied; in most previous cohort studies, the number of women ranged from one to $12 .{ }^{47121316-18}$ More cases $(n=45)$ were included in another study, ${ }^{19}$ although that study consisted of a mixture of non-epithelial, epithelial, and borderline ovarian tumours. Thus all the earlier cohort studies were limited by imprecise risk estimates, especially in subgroups of fertility drug users. Furthermore, only two cohort studies ${ }^{419}$ had a suitable reference group - that is, a control group of infertile women who had not taken fertility drugs. The others used standardised incidence ratios to compare the risk of ovarian cancer in cohorts of infertile women with that of the general population. This comparison controls for the potential confounders of age and calendar time but not for parity, causes of infertility, and oral contraceptive use.

We showed previously that the infertile women in this cohort are at a higher risk of ovarian cancer than women in the general Danish population, even after adjustment for parity. ${ }^{27}$ The case-cohort technique used in the present study, however, showed no strong association between use of fertility drugs and risk of ovarian cancer in the cohort. Our data therefore suggest that factors related to the diagnosis of infertility (for example, genetic or biological), and not the use of fertility drugs, increase the overall risk of ovarian cancer. One strength of our study is the virtual absence of losses to follow-up, as a result of the precise linkage between our cohort and the Danish population based registers and complete ascertainment of diagnoses for ovarian cancer. Furthermore, we had detailed information on the various types of fertility drugs used, which allowed examination of their potentially different effects. Few of the previous cohort studies ${ }^{4121319}$ and case-control studies ${ }^{61020}$ were able to assess the effects of different types of fertility drugs.

Table 4 | Rate ratios for histological subgroups of ovarian cancer according to use of fertility drugs

\begin{tabular}{|c|c|c|c|c|c|c|c|c|c|c|}
\hline \multirow{2}{*}{$\begin{array}{l}\text { Fertility drugs } \\
\text { and use }\end{array}$} & \multicolumn{5}{|c|}{ No with ovarian cancer/No in subcohort } & \multicolumn{5}{|c|}{ Adjusted rate ratio $(95 \% \mathrm{Cl})$} \\
\hline & Serous & Mucinous & Endometrioid & Clear cell & Other & Serous & Mucinous & Endometrioid & Clear cell & Other \\
\hline \multicolumn{11}{|c|}{ Gonadotrophins*: } \\
\hline Never & 72/1057 & 9/1057 & $21 / 1057$ & 6/1057 & $22 / 1057$ & 1.00 & 1.00 & 1.00 & 1.00 & 1.00 \\
\hline Ever & $18 / 184$ & $3 / 184$ & $2 / 184$ & $2 / 184$ & $1 / 184$ & $\begin{array}{c}1.04 \\
\text { (0.57 to } 1.90)\end{array}$ & $\begin{array}{c}1.14 \\
\text { (0.33 to } 3.99)\end{array}$ & $\begin{array}{c}0.74 \\
\text { (0.19 to } 2.93)\end{array}$ & $\begin{array}{c}1.59 \\
\text { (0.34 to } 7.55)\end{array}$ & $\begin{array}{c}0.57 \\
(0.14 \text { to } 2.28)\end{array}$ \\
\hline \multicolumn{11}{|c|}{ Clomifene citrate: } \\
\hline Never & $48 / 824$ & $9 / 824$ & $19 / 824$ & $4 / 824$ & $18 / 824$ & 1.00 & 1.00 & 1.00 & 1.00 & 1.00 \\
\hline Ever & $42 / 417$ & $3 / 417$ & $4 / 417$ & $4 / 417$ & $5 / 417$ & $\begin{array}{c}1.67 \\
\text { (1.07 to } 2.61)\end{array}$ & $\begin{array}{c}0.60 \\
\text { (0.18 to } 2.08)\end{array}$ & $\begin{array}{c}0.68 \\
(0.27 \text { to } 1.67)\end{array}$ & $\begin{array}{c}1.62 \\
(0.55 \text { to } 4.74)\end{array}$ & $\begin{array}{c}0.70 \\
\text { (0.29 to } 1.73)\end{array}$ \\
\hline \multicolumn{11}{|l|}{ hCG: } \\
\hline Never & $54 / 828$ & $8 / 828$ & $18 / 828$ & $6 / 828$ & $21 / 828$ & 1.00 & 1.00 & 1.00 & 1.00 & 1.00 \\
\hline Ever & $36 / 413$ & $4 / 413$ & $5 / 413$ & $2 / 413$ & $2 / 413$ & $\begin{array}{c}1.29 \\
\text { (0.83 to } 2.01)\end{array}$ & $\begin{array}{c}0.61 \\
(0.20 \text { to } 1.79)\end{array}$ & $\begin{array}{c}0.68 \\
(0.28 \text { to } 1.67)\end{array}$ & $\begin{array}{c}0.44 \\
\text { (0.10 to } 1.92)\end{array}$ & $\begin{array}{c}0.24 \\
\text { (0.08 to } 0.79)\end{array}$ \\
\hline \multicolumn{11}{|l|}{ GnRH: } \\
\hline Never & $80 / 1131$ & $11 / 1131$ & $22 / 1131$ & $6 / 1131$ & $22 / 1131$ & 1.00 & 1.00 & 1.00 & 1.00 & 1.00 \\
\hline Ever & $10 / 110$ & $1 / 110$ & $1 / 110$ & $2 / 110$ & $1 / 110$ & $\begin{array}{c}0.93 \\
\text { (0.44 to } 1.98)\end{array}$ & $\begin{array}{c}1.47 \\
\text { (0.26 to } 8.21)\end{array}$ & $\begin{array}{c}0.75 \\
\text { (0.13 to 4.38) }\end{array}$ & $\begin{array}{c}2.89 \\
\text { (0.54 to } 15.54)\end{array}$ & $\begin{array}{c}1.14 \\
(0.27 \text { to } 4.85)\end{array}$ \\
\hline
\end{tabular}

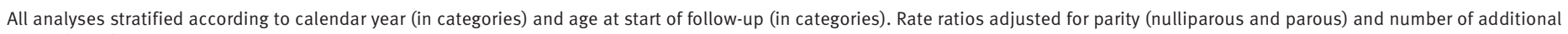
births (linear). hCG=human chorionic gonadotrophins; $\mathrm{GnRH}=$ gonadotrophin releasing hormone.

*Follicle stimulating hormone and human menopausal gonadotrophins. 
Our study does have limitations. Even though we had a relatively long follow-up period, the median age at the end of follow-up (47 years) was below the usual peak age (early 60s) for ovarian cancer, which might have weakened our estimates. Potentially important risk factors such as the cause of infertility and use of oral contraceptives were registered for only a few of the women and could therefore be analysed only for the subsets that included this information. In line with most previous studies, ${ }^{13151920}$ however, our results show that adjustment for oral contraceptive use and causes of infertility does not change the risk estimates markedly. Furthermore, we found no association between oral contraceptive use and use of fertility drugs or between causes of infertility and use of fertility drugs (data not shown), which thus add further weight that our results are not an artefact due to uncontrolled confounding by these factors. However, as several studies have shown that certain causes of infertility might be linked independently to ovarian cancer, ${ }^{4-1523-2634}$ both our results and those of previous studies might partly reflect methodological differences and weaknesses in assessment of the causes of infertility. For example, researchers may not have complete knowledge of the extent to which a woman has been evaluated for all causes of infertility. Clearly this topic needs further assessment in future studies.

\section{Comparisons with the literature}

Two theories are usually used to explain how fertility drugs might affect the risk of ovarian cancer. The incessant ovulation theory suggests that repeated, uninterrupted ovulation causes microtrauma to the ovarian epithelium, leading to malignant transformations. ${ }^{35}$ The gonadotrophin theory suggests that exposure of the ovaries to endogenous or exogenous gonadotrophins is directly carcinogenic. ${ }^{36}$ Even though these theories are biologically plausible, only two epidemiological studies, ${ }^{45}$ done in the early 1990 s, found a notable association between use of fertility drugs and the risk of invasive ovarian cancer. The main finding in one retrospective cohort study ${ }^{4}$ was a relative risk of 11.1 (95\% confidence interval 1.50 to 82.3) among infertile women with long term exposure to clomifene ( $\geq 12$ cycles); however, the results of this study are difficult to interpret because of the small number of cases and the limited information on confounding factors. The other study that has undergone close scrutiny is the collaborative analysis of 12 case-control studies in the United States. ${ }^{5}$ The risk of ovarian cancer was dramatically increased among nulligravid women who used fertility drugs (rate ratio 27, 95\% confidence interval 2.30 to 315.60 ), but interpretation of the results is difficult as information on use of specific types of fertility drug was not available. In the US study ${ }^{5}$ the indication of a causal relation between fertility drugs and ovarian cancer is also hampered by a low statistical precision of the risk estimate (wide confidence intervals) because only a limited number of controls had used fertility drugs. Furthermore, the validity of the study has also been questioned by others owing to the possible role of several potential biases, including diagnostic bias, selection bias, and recall bias. ${ }^{37}$

Our results contrast with those of the two epidemiological studies ${ }^{45}$ but are in line with those of most subsequent epidemiological studies ${ }^{7-21}$ and are generally reassuring, as we found no difference in overall risk of ovarian cancer according to any use of the four groups of fertility drug studied, number of cycles of use, length of follow-up since first use, and parity. The absence of a dose-response relation between the number of cycles and the risk of ovarian cancer found in our study is in line with most previous findings, ${ }^{81117-20}$ but not all. ${ }^{4}$ Only one study ${ }^{19}$ also examined the association between the risk of ovarian cancer and follow-up since first use of fertility drugs, and, as with our study, found no convincing association. Both our results and those of that study ${ }^{19}$ are, however, limited as only a small proportion of the women in the cohorts were followed up for a sufficient time. Longer follow-up is needed to assess the effect of latency on risk of ovarian cancer after exposure to fertility drugs.

The collaborative analysis of 12 case-control studies in the United States ${ }^{5}$ suggested that infertile women who received fertility drugs but remained nulliparous may be at particularly high risk. This result is in line with those of two subsequent studies that found statistically non-significantly increased risks among women who remained nulliparous. ${ }^{1519}$ However, our study, in line with others, ${ }^{101420}$ found no association between overall risk of ovarian cancer and use of fertility drugs after stratifying for parity. Further investigations on this topic are warranted.

The detailed histological information contained in the Danish Cancer Registry and the Danish Registry of Pathology, in combination with the large number of cases of ovarian cancer in our cohort, enabled us to analyse potential differences in risk according to histological subtype. In contrast to the analyses of overall risk of ovarian cancer, we found a significant $67 \%$ increase in risk of serous tumours after use of clomifene, primarily when follow-up was for more than 15 years since first use. The risks for mucinous, endometrioid, and clear cell tumours were not significantly affected by use of any of the four types of fertility drugs. No previous cohort study has addressed the association between infertility and risk of ovarian cancer according to histological type. In a pooled analysis of case-control studies, however, researchers ${ }^{15}$ found no association between use of fertility drugs and the risks for the different histological subtypes of epithelial ovarian tumours. Several studies have suggested that mucinous tumours are less affected by hormonal (oral contraceptives) and parity related factors than non-mucinous tumours. ${ }^{38-44}$ It is therefore plausible that the carcinogenic effect of fertility drugs is less pronounced for mucinous tumours. However, only the risk estimates for the association between use of fertility drugs and serous tumours can be considered to be based on a sufficiently large number of cases to 


\section{WHAT IS ALREADY KNOWN ON THIS TOPIC}

Most epidemiological studies have found no strong link between use of fertility drugs and risk of ovarian cancer, but controversy persists

Most earlier cohort studies have had methodological problems

\section{WHAT THIS STUDY ADDS}

No convincing association was found between overall risk of ovarian cancer and use of fertility drugs

Follow-up is needed as many of the women in the cohort have not yet reached the peak age for ovarian cancer
1 Modugno F, Ness RB, Wheeler JE. Reproductive risk factors for epithelial ovarian cancer according to histologic type and invasiveness. Ann Epidemiol 2001;11:568-74.

2 Hankinson SE, Colditz GA, Hunter DJ, Willett WC, Stampfer MJ, Rosner B, et al. A prospective study of reproductive factors and risk of epithelial ovarian cancer. Cancer 1995;76:284-90.

3 Risch HA, Marrett LD, Howe GR. Parity, contraception, infertility, and the risk of epithelial ovarian cancer. Am J Epidemiol 1994;140:585-97.

4 Rossing MA, Daling JR, Weiss NS, Moore DE, SelfSG. Ovarian tumors in a cohort of infertile women. N Engl J Med 1994;331:771-6.

5 Whittemore AS, Harris R, Itnyre J. Characteristics relating to ovarian cancer risk: collaborative analysis of 12 US case-control studies. II. Invasive epithelial ovarian cancers in white women. Collaborative Ovarian Cancer Group. Am J Epidemiol 1992;136:1184-203.

6 Shushan A, Paltiel O, Iscovich J, Elchalal U, Peretz T, Schenker JG. Human menopausal gonadotropin and the risk of epithelial ovarian cancer. Fertil Steril 1996;65:13-8.

7 Venn A, Watson L, Lumley J, Giles G, King C, Healy D. Breast and ovarian cancer incidence after infertility and in vitro fertilisation. Lancet 1995;346:995-1000.

enable a high precision of the risk estimates. Therefore although the association between use of clomifene and risk of serous tumours may be real and important, we are not able to draw firm conclusions on the other histological types of ovarian cancer as the low precision of the risk estimates for other histological subtypes than serous tumours makes it hard to determine whether they do differ from the risk estimates for serous tumours. Also, we cannot rule out the possibility that the positive association between use of clomifene and risk of serous tumours arose from multiple comparisons. Further long term follow-up studies are therefore needed to confirm our findings.

\section{Conclusions}

The results of our large, nationwide study, which represents the largest number of cases of ovarian cancer in any cohort of women with infertility problems to date, generally concur with those of most previous epidemiological studies and provide reassuring evidence for the absence of a strong association between use of fertility drugs and risk of ovarian cancer. However, as many of the women in our cohort have not yet reached the usual peak age for ovarian cancer, we will continue to monitor the risk to try to establish a more definite link between use of fertility drugs and risk of ovarian cancer. In a society where infertility in women and maternal age at birth of the first child are increasing, the unfavourable effects of fertility drugs (for example, a possible small increase in risk of ovarian cancer) should be balanced against the physical and psychological benefits of a pregnancy made possible only by the use of these drugs.

We thank Nick Martinussen for help with data management and all participating hospital departments and private fertility clinics for help with the data collection.

Contributors: SKK and HS established the Danish infertility cohort. All authors contributed to the planning and reporting of the work and had final responsibility for writing the manuscript and the decision to submit it for publication. SKK is the guarantor.

Funding: This research was supported by the Danish Cancer Society. The funding sources were not involved in the study design or data collection, analyses, interpretation of the results, the decision to submit the manuscript for publication, or the writing of the manuscript. Competing interests: None declared.

Ethical approval: This study was approved by the scientific ethics committee of Copenhagen and Frederiksberg municipalities and the Danish Data Protection Agency.
8 Venn A, Watson L, Bruinsma F, Giles G, Healy D. Risk of cancer after use of fertility drugs with in-vitro fertilisation. Lancet 1999;354:1586-90.

9 Franceschi S, La Vecchia C, Negri E, Guarneri S, Montella M, Conti E, et al. Fertility drugs and risk of epithelial ovarian cancer in Italy. Hum Reprod 1994:9:1673-5.

10 Mosgaard BJ, Lidegaard O, Kjaer SK, Schou G, Andersen AN. Infertility, fertility drugs, and invasive ovarian cancer: a case-control study. Fertil Steril 1997;67:1005-12.

11 Parazzini F, Negri E, La Vecchia C, Moroni S, Franceschi S, Crosignani PG. Treatment for infertility and risk of invasive epithelial ovarian cancer. Hum Reprod 1997:12:2159-61.

12 Modan B, Ron E, Lerner-Geva L, Blumstein T, Menczer J, Rabinovici J, et al. Cancer incidence in a cohort of infertile women. Am J Epidemiol 1998;147:1038-42.

13 Potashnik G, Lerner-Geva L, Genkin L, Chetrit A, Lunenfeld E, Porath A. Fertility drugs and the risk of breast and ovarian cancers: results of a long-term follow-up study. Fertil Steril 1999;71:853-9.

14 Parazzini F, Pelucchi C, Negri E, Franceschi S, Talamini R, Montella M, et al. Use of fertility drugs and risk of ovarian cancer. Hum Reprod 2001;16:1372-5.

15 Ness RB, Cramer DW, Goodman MT, Kjaer SK, Mallin K, Mosgaard BJ, et al. Infertility, fertility drugs, and ovarian cancer: a pooled analysis of case-control studies. Am / Epidemiol 2002;155:217-24.

16 Doyle P, Maconochie N, Beral V, Swerdlow AJ, Tan SL. Cance incidence following treatment for infertility at a clinic in the UK. Hum Reprod 2002;17:2209-13.

17 Dor J, Lerner-Geva L, Rabinovici J, ChetritA, Levran D, Lunenfeld B, et al. Cancer incidence in a cohort of infertile women who underwent in vitro fertilization. Fertil Steril 2002;77:324-7.

18 Lerner-Geva L, Geva E, Lessing JB, Chetrit A, Modan B, Amit A. The possible association between in vitro fertilization treatments and cancer development. Int / Gynecol Cancer 2003;13:23-7.

19 Brinton LA, Lamb EJ, Moghissi KS, Scoccia B, Althuis MD, Mabie JE, et al. Ovarian cancer risk after the use of ovulation-stimulating drugs. Obstet Gynecol 2004;103:1194-203.

20 Rossing MA, Tang MT, Flagg EW, Weiss LK, Wicklund KG. A casecontrol study of ovarian cancer in relation to infertility and the use of ovulation-inducing drugs. Am J Epidemiol 2004;160:1070-8.

21 Kashyap S, Moher D, Fung MF, Rosenwaks Z. Assisted reproductive technology and the incidence of ovarian cancer: a meta-analysis. Obstet Gynecol 2004;103:785-94.

22 Brinton LA, Moghissi KS, Scoccia B, Westhoff CL, Lamb EJ. Ovulation induction and cancer risk. Fertil Steril 2005;83:261-74.

23 Brinton LA, Gridley G, Persson I, Baron J, Bergqvist A. Cancer risk aftera hospital discharge diagnosis of endometriosis. Am J Obstet Gynecol 1997;176:572-9.

24 Meirow D, Schenker JG. The link between female infertility and cancer: epidemiology and possible aetiologies. Hum Reprod Update 1996;2:63-75.

25 Oral E, llvan S, Tustas E, Korbeyli B, Bese T, Demirkiran F, et al. Prevalence of endometriosis in malignant epithelial ovary tumours. Eur J Obstet Gynecol Reprod Biol 2003;109:97-101.

26 Schildkraut JM, Schwingl PJ, Bastos E, Evanoff A, Hughes C. Epithelia ovarian cancer risk among women with polycystic ovary syndrome. Obstet Gynecol 1996;88:554-9.

27 Jensen A, Sharif H, Olsen JH, Kjaer SK. Risk of breast cancer and gynecologic cancers in a large population of nearly 50,000 infertile Danish women. Am J Epidemiol 2008;168:49-57.

28 Jensen A, Sharif H, Svare El, Frederiksen K, Kjaer SK. Risk of breast cancer after exposure to fertility drugs: results from a large Danish cohort study. Cancer Epidemiol Biomarkers Prev 2007;16:1400-7. 
29 Hannibal CG, Jensen A, Sharif H, Kjaer SK. Risk of thyroid cancer afte exposure to fertility drugs: results from a large Danish cohort study. Hum Reprod 2008;23:451-6.

30 Hannibal CG, Jensen A, Sharif H, Kjaer SK. Malignant melanoma risk after exposure to fertility drugs: results from a large Danish cohort study. Fertil Steril 2008;19:759-65.

31 Prentice RL. A case-cohort design for epidemiological cohort studies and disease prevention trials. Biometrika 1986;73:1-11.

32 Barlow WE, Ichikawa L, Rosner D, Izumi S. Analysis of case-cohort designs. J Clin Epidemiol 1999;52:1165-72.

33 Barlow WE. Robust variance estimation for the case-cohort design. Biometrics 1994;50:1064-72.

34 Brinton LA, Lamb EJ, Moghissi KS, Scoccia B, Althuis MD, Mabie JE, et al. Ovarian cancer risk associated with varying causes of infertility. Fertil Steril 2004;82:405-14.

35 La Vecchia C, Franceschi S, Gallus G, Decarli A, Liberati A, Tognoni G. Incessant ovulation and ovarian cancer: a critical approach. Int J Epidemiol 1983;12:161-4.

36 Clinton GM, Hua W. Estrogen action in human ovarian cancer. Crit Rev Oncol Hematol 1997;25:1-9.

37 Althuis MD, Moghissi KS, Westhoff CL, Scoccia B, Lamb EJ, Lubin JH, et al. Uterine cancer after use of clomiphene citrate to induce ovulation. Am J Epidemiol 2005;161:607-15.
38 Risch HA, Marrett LD, Jain M, Howe GR. Differences in risk factors for epithelial ovarian cancer by histologic type. Results of a case-control study. Am J Epidemiol 1996;144:363-72.

39 Riman T, Dickman PW, Nilsson S, Correia N, Nordlinder H, Magnusson CM, et al. Risk factors for invasive epithelial ovarian cancer: results from a Swedish case-control study. Am J Epidemiol 2002;156:363-73.

40 Purdie DM, Webb PM, Siskind V, Bain CJ, Green AC. The different etiologies of mucinous and nonmucinous epithelial ovarian cancers. Gynecol Oncol 2003;88:145-8.

41 Parazzini F, Chiaffarino F, Negri E, Surace M, Benzi G, Franceschi S, et al. Risk factors for different histological types of ovarian cancer. Int Gynecol Cancer 2004;14:431-6.

42 Purdie DM, Siskind V, Bain CJ, Webb PM, Green AC. Reproductionrelated risk factors for mucinous and nonmucinous epithelial ovarian cancer. Am / Epidemiol 2001;153:860-4.

43 Kurian AW, Balise RR, McGuire V, Whittemore AS. Histologic types of epithelial ovarian cancer: have they different risk factors? Gynecol Oncol 2005;96:520-30.

44 Soegaard M, Jensen A, Hoegdall E, Christensen L, Hoegdall C, Blaakaer J, et al. Different risk factor profiles for mucinous and nonmucinous ovarian cancer. Results from the Danish MALOVA study. Cancer Epidemiol Biomarkers 2007;16:1160-6.

Accepted: 11 November 2008 